\title{
Follow-up of the WHO multinational study of vascular disease in diabetes: general description and morbidity
}

\author{
E. T. Lee ${ }^{1}$, H. Keen ${ }^{2}$, P.H. Bennett ${ }^{3}$, J.H. Fuller ${ }^{4}$, M. Lu ${ }^{1}$ and the WHO Multinational Study Group* \\ ${ }^{1}$ Centre for American Indian Health Research and Department of Biostatistics and Epidemiology, College of Public Health, \\ University of Oklahoma Health Sciences Centre, Oklahoma City, USA \\ ${ }^{2}$ Unit for Metabolic Medicine, Guy's Hospital, London, UK \\ ${ }^{3}$ Phoenix Epidemiology and Clinical Research Branch, NIDDK, Phoenix, Arizona, USA \\ ${ }^{4}$ EURODIAB, Department of Epidemiology and Public Health, University College, London, UK
}

\section{Abstract}

Aims. The incidence of retinal, renal and cardiovascular complications and their relation to baseline risk factors was documented in this follow-up study of 10 of the 14 original centres of the WHO Multinational Study of Vascular Disease in Diabetes (WHO MSVDD).

Methods. The incidence of specified items of vascular disease and some associated risk factors was ascertained after 7 to 9 years (11-12 years in Oklahoma, USA) follow-up, re-using baseline examination methodology in 3165 patients $(66.9 \%)$ and, through secondary information in $717(15.2 \%)$ of the 4729 original patients, of whom $540(11.4 \%)$ had died and $307(6.5 \%)$ were untraceable.

Results. During follow-up, approximately one third of the patients developed hypertension and one third started insulin. Coronary heart disease incidence varied 10 to 20-fold among centres as did limb amputation rates. Inter-centre differences in incident retinopathy and severe visual impairment were smaller but incident clinical proteinuria and renal failure var- ied markedly. Vascular disease incidence of all categories was high in Native Americans though coronary heart disease incidence was relatively low in Pima Indians and absolutely low in Hong Kong and Tokyo patients. Specific vascular events and their relation with baseline risk factors are analysed in accompanying papers, summarised in the Epilogue.

Conclusion/interpretation. These 10 centres reported very different incidence rates of vascular complications. Observer variation, selection biases and competing causes of mortality contributed to these differences but their validity is supported by the more objective outcome indicators. The following papers also suggest that baseline factors such as raised arterial pressure, cholesterol and fasting glucose (in the centres where it was measured) were important and potentially reversible predictors of risk. [Diabetologia (2001) 44 [Suppl 2]: S3-S 13]

Keywords diabetes mellitus, retinopathy, nephropathy, amputation, atherosclerosis, hypertension, incidence, epidemiology, ethnicity, multinational study.
The Multinational Study of Vascular Disease in Diabetes, sponsored by the World Health Organization (WHO MSVDD), was initiated in 1974 to compare the prevalence of vascular complications in samples of people with diabetes from 14 centres of different

Corresponding author: Elisa T. Lee, PhD, College of Public Health, University of Oklahoma Health Sciences Centre, P.O. Box 26901, Oklahoma City, OK 73190, USA

Abbreviations: WHO MSVDD, World Health Organization Multinational Study of Vascular Disease in Diabetes; MI, myocardial infarction; PDR, proliferative diabetic retinopathy.

\footnotetext{
* See Appendix 2 for list of investigators
}

geographical, ethnic and cultural backgrounds. The original participating centres were London, Switzerland, Brussels, Moscow, Warsaw, Berlin, Zagreb, Bulgaria, New Delhi, Hong Kong, Tokyo, Havana, Oklahoma and Arizona. In Oklahoma and Arizona, all participants were Native Americans. Subjects attended a personal interview, a physical examination and standardised tests. Details of the procedures used and results of this prevalence study have been published elsewhere [1,2].

Ten of the 14 centres (London, Switzerland, Warsaw, Zagreb, Hong Kong, Tokyo, Havana, Oklahoma, and Arizona) participated in a follow-up study 
initiated in 1983 and completed in the latest centre (Oklahoma) in 1990. Its main objectives were: firstly, to compare all-cause-specific and disease-specific mortality rates in the participating centres; secondly, to compare the incidence of specified items of morbidity from macrovascular and microvascular disease in the centres; and thirdly to relate baseline variables to mortality and/or morbidity outcomes and explore between-centre differences.

The follow-up was divided in two parts, a mortality survey and a morbidity follow-up. For the former, the life or death status of all patients included in the prevalence study was ascertained up to January 1, 1983. For those deceased, death certificates and, if obtainable, autopsy reports and clinical summaries were collected and reviewed. All data were submitted to the mortality analysis centre in London where causes of death were determined according to ICD-9 codes by a mortality review committee. Some aspects of the international variation in mortality and associations have been reported [3, 4].

For the morbidity study, all survivors were invited for interview and examination using a protocol closely similar to that of the prevalence study. In those who were not re-examined, 'secondary information' from personal visits, health care providers and medical records was systematically reviewed for evidence of specified conditions and diabetes related complications. This paper presents a summarised, overall description of the incidence of vascular outcomes and reports rates of incident macrovascular and microvascular events when the date of first record was noted.

More detailed analyses of specific items of morbidity and mortality, the risk factors associated with them, their distribution by centre and their demographic and clinical characteristics appear in accompanying papers to which the following detailed Subjects, Methods and Definitions section also apply.

\section{Subjects and methods}

For the original study, each centre aimed to recruit stratified samples of 250 men and 250 women with a clinical diagnosis of diabetes, aged between 35 and 54 years at recruitment, and falling into specified duration categories of diabetes. This baseline prevalence study was conducted between 1975 and 1978. In Oklahoma a few patients were also recruited in 1973 to 1974 and in 1979 to 1980 . The life-death status of all recruits was ascertained as of the 1st of January 1983. In addition, all surviving patients were invited for an interview and an examination which included demographic information, medical history including the WHO Cardiovascular Questionnaire for history of angina pectoris, myocardial infarction and intermittent claudication [5], smoking status and current medical conditions. After standard questionnaires, all patients were also asked directly whether they had ever received a clinical diagnosis of angina pectoris, heart attack or stroke, had undergone renal dialysis or experienced ischaemic gangrene or amputation. The date of first occurrence of any such event was record- ed. Previous medical history also included the year diabetes was first diagnosed, current treatment for diabetes, and the use of other medications (including diuretics, lipid lowering drugs, and blood pressure lowering drugs) and where possible these were verified from medical records. Measurement of height, weight, systolic and diastolic blood pressure, 12-lead ECG, standardised, dilated eye fundus examination and laboratory tests of blood and urine were carried out as at baseline. As then, hypertension was defined as a systolic blood pressure of $160 \mathrm{mmHg}$ or more, or a diastolic blood pressure of $95 \mathrm{mmHg}$, or more, or treatment with antihypertensive medications, including diuretics. All ECG's were Minnesota coded independently by the same two experienced readers who had processed the baseline ECG's. Follow-up blood and urine samples were analysed at the Laboratory Centre in Phoenix, Arizona for plasma creatinine (Technicon SE 20011FM-3), urinary protein (Albustix) and quantitative albumin concentration [6]. Microalbuminuria is defined in Appendix 1. Fasting blood glucose and triglyceride had been measured at baseline in 8 and 5 of the 10 follow-up centres respectively.

For those unwilling or unable to attend the follow-up, reasons for this failure were sought. Non-responders and patients never relocated were classified as losses-to-follow-up. Reasons for loss to follow-up included death after January 1, 1983 (date of life-death ascertainment), serious ill health, distance from examiners, lack of cooperation and inability to establish contact. For each non-attender, systematic efforts were made to ascertain study outcomes by personal visit, record review, and from questions to health care providers or other informants. Renal failure, visual loss, stroke, heart attack, angina pectoris, and ischaemic gangrene and/or amputation were specifically sought with onset date if positive. Data were managed and analysed at the Data Collaborating Centre in Oklahoma.

The follow-up examinations took place between 1983 and 1986 (in Oklahoma between 1988 and 1990). The mean duration of follow-up for all centres was approximately $8.4 \pm$ 2.8 years (Oklahoma, 11.7 years). Medical record review for non-respondents was carried out at the time of follow-up examination or immediately afterwards, except in Zagreb where this ascertainment was within 18 months of the examinations.

Incident cases were defined as those with an index event that had occurred between baseline and follow-up. Events identified at follow-up examination were recorded on Form IIA and those from secondary information sources on Form IIB (Appendix 1). Persons who did not have vascular disease at baseline examination and who died before January 1, 1983 were counted as incident cases when an index event was the underlying or a contributing cause of death. The estimated incidence rate of events when the date of occurrence was available, was based on the observational person-years (date of baseline examination to the date of the first event or date of death for decedents). These events include a new history of angina pectoris, myocardial infarction (MI), stroke, ischaemic gangrene and/or amputation, visual loss and renal failure (Appendix 1). When the date of the first event was unknown, the midpoint of the follow-up period for that person was used for the estimate. Cumulative incidence rates were also calculated for ECG abnormality, for appearance of any retinopathy, proliferative diabetic retinopathy (PDR) and severe visual impairment, and for proteinuria (Appendix 1).

The working definition of Type I (insulin-dependent) diabetes mellitus applied to patients who had started insulin less than one year from diagnosis; all other patients were classified as having Type II (non-insulin-dependent) diabetes mellitus. These simple clinical definitions with acknowledged inadequacies were used given the constraints on information available and for consistency with earlier analyses $[7,8]$. 
Table 1. Follow-up status by centre

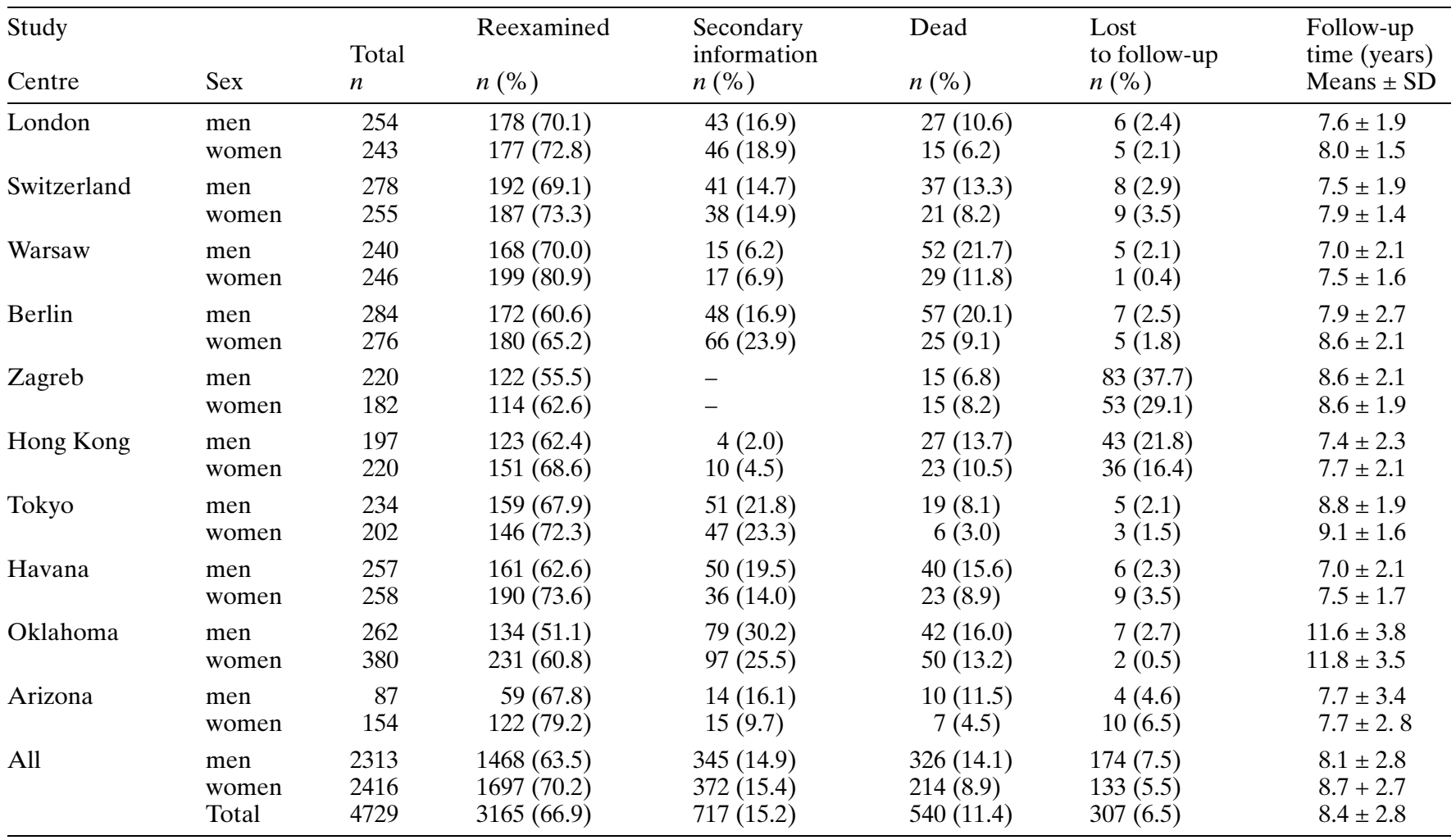

We also record changes in smoking habit, diabetes treatment, body mass index, and hypertension status which occurred during the follow-up period. Statistical analysis for this and accompanying papers included use of the chi-square statistic, Student's $t$ test, analysis of variance and stepwise linear logistic regression $[9,10]$.

\section{Results}

The follow-up rates, reasons for non-participation, and differences between participants and non-participants were as follows: a total of 4729 diabetic patients (2313 men and 2416 women) at the 10 centres qualified to enter the follow-up. Of the 4746 subjects from these centres in the 1985 prevalence analysis [2], 17 were excluded as having been found non-diabetic, as lying outside the age range, or representing duplicated records. The status and follow-up duration for each centre (Table 1) show that $540(11.48 \%$ ) patients had died on or before January 1, 1983 and $3165(66.93 \%)$ were re-examined at follow-up. The overall ascertainment rate was over $93 \%$ in all centres except Zagreb and Hong Kong.

Those who died before follow-up examination were older at baseline, more likely to be men, with longer duration of diabetes, higher blood pressures, diagnosed more often as hypertensive and with proteinuria, with higher values of blood cholesterol and, fasting plasma glucose and triglycerides in the centres where it was measured. More were smokers, had a history of macrovascular disease and were found to have retinopathy. Surviving non-participants also shared these characteristics and were also older at diagnosis, had shorter duration of diabetes and higher BMI and were more likely to be treated with insulin.

Of the $307(6.49 \%)$ patients lost-to-follow-up, over $70 \%$ (215) were from Zagreb and Hong Kong. In the former, they were more likely to be older, to have a higher blood pressure, more likely to have insulin treatment, and to have had higher prevalence of retinopathy and macrovascular complications than other participants at baseline. In the latter, they did not differ significantly from other participants.

Metabolic Characteristics. In a subset of 9 of the original 14 centres, 8 of them included in the follow-up, fasting venous blood was collected at the baseline examination and glucose estimated by the local 'true glucose' method. The methods used have been described elsewhere [11]. The geometric mean fasting glucose values are shown by centre in Table 2 . In patients classed as having Type I diabetes, the mean glucose values did not differ systematically between men and women. They were all higher than in the patients with Type II diabetes from the same centres in which mean values in women exceeded those in men in all but one centre. Mean glucose values in Type II diabetic patients at the Oklahoma and Arizona centres exceeded those in all the others. At 5 of these centres, 
Table 2. Mean fasting plasma glucose ( $\mathrm{mmol} / \mathrm{l})$ by centre

\begin{tabular}{llccc}
\hline Centre & \multicolumn{2}{c}{ Type I (insulin-dependent) diabetes mellitus } & \multicolumn{2}{c}{ Type II (non-insulin-dependent) diabetes mellitus } \\
\hline & Men & Women & Men & Women \\
& Mean $^{\mathrm{a}}(95 \% \mathrm{CI})$ & Mean $^{\mathrm{a}}(95 \% \mathrm{CI})$ & Mean $^{\mathrm{a}}(95 \% \mathrm{CI})$ & $\mathrm{Mean}(95 \% \mathrm{CI})$ \\
\hline London & $13.6(12.2,15.2)$ & $12.5(10.4,15.0)$ & $8.2(6.9,9.9)$ & $9.7(8.2,11.4)$ \\
Switzerland & $8.9(7.7,10.3)$ & $10.5(9.2,11.8)$ & $9.0(8.3,9.0)$ & $9.4(8.7,10.1)$ \\
Warsaw & $12.4(11.3,13.7)$ & $15.0(13.7,16.4)$ & $7.6(7.2,7.9)$ & $9.0(8.4,9.6)$ \\
Berlin & $11.9(10.5,13.4)$ & $11.3(9.8,13.0)$ & $8.0(7.6,8.4)$ & $7.7(7.3,8.1)$ \\
Tokyo & $8.9(7.8,10.0)$ & $8.6(7.1,10.4)$ & $7.2(6.6,7.8)$ & $8.3(7.9,8.7)$ \\
Havana & $9.1(7.5,11.2)$ & $10.2(8.5,12.1)$ & $9.6(9.2,10.1)$ & $7.4(6.9,10.8)$ \\
Oklahoma & $10.4(9.0,12.0)$ & $10.7(8.7,13.2)$ & $10.6(9.8,11.5)$ & $10.3(9.9,10.8)$ \\
Arizona & - & - & $8.4(8.2,8.7)$ & $13.0(12.3,13.8)$ \\
Total & $10.8(10.2,11.4)$ & $11.6(10.9,12.4)$ & $9.3(9.1,9.5)$ \\
\hline
\end{tabular}

${ }^{\text {a geometric mean }}$

Table 3. Mean fasting serum triglyceride ( $\mathrm{mmol} / \mathrm{l})$ by centre

\begin{tabular}{lllll}
\hline Centre & \multicolumn{2}{l}{ Type I (insulin-dependent) diabetes mellitus } & \multicolumn{2}{l}{ Type II (non-insulin-dependent) diabetes mellitus } \\
\hline & $\begin{array}{l}\text { Men } \\
\operatorname{Mean}^{\mathrm{a}}(95 \% \mathrm{CI})\end{array}$ & $\begin{array}{l}\text { Women } \\
\operatorname{Mean}^{\mathrm{a}}(95 \% \mathrm{CI})\end{array}$ & $\begin{array}{l}\text { Men } \\
\text { Mean }^{\mathrm{a}}(95 \% \mathrm{CI})\end{array}$ & $\begin{array}{l}\text { Women } \\
\text { Mean }\end{array}$ \\
& $1.16(0.98,1.36)$ & $0.97(0.85,1.11)$ & $1.24(1.02,1.51)$ & $1.28(1.01,1.61)$ \\
London & $1.11(0.96,1.27)$ & $1.07(0.97,1.19)$ & $1.76(1.57,1.97)$ & $1.69(1.50,1.89)$ \\
Switzerland & $1.46(1.33,1.61)$ & $1.46(1.32,1.61)$ & $1.74(1.57,1.93)$ & $1.64(1.52,1.78)$ \\
Warsaw & $1.60(1.39,1.86)$ & $1.24(1.09,1.41)$ & $1.76(1.60,1.93)$ & $1.67(1.52,1.84)$ \\
Berlin & $2.30(1.81,2.92)$ & $2.00(1.59,2.53)$ & $2.20(2.01,2.41)$ & $2.06(1.93,2.19)$ \\
Oklahoma & $1.43(1.33,1.53)$ & $1.26(1.18,1.34)$ & $1.87(1.78,1.97)$ & $1.82(1.75,1.90)$ \\
Total & & &
\end{tabular}

${ }^{a}$ geometric mean

total plasma triglyceride concentration was also measured by an enzymatic method [20] in the fasting blood samples. Geometric mean triglyceride values are shown in Table 3. They were all higher in the Oklahoma centre than in the other 4, at each of which concentrations in patients with Type II diabetes exceeded those with Type I diabetes.

Distributions of variables at follow-up and changes observed. Summary statistics of several variables (age, duration of diabetes, type of diabetes, type of treatment, hypertension status and smoking status) recorded at follow-up by centre and sex are presented in Table 4 with body mass index at follow-up in Figure 1. Mean known duration of diabetes ranged from about 15 years in Hong Kong to 22 years in London. Average systolic and diastolic pressures in women were substantially lower in Arizona than in all other centres. Hypertension as a category was present in over one third of all men and almost one half of all women with its highest frequency in women from Berlin $(56 \%)$ and lowest in men from London $(21.5 \%)$. Of the 2129 persons non-hypertensive at baseline, $31.7 \%$ met the criteria for hypertension when assessed at follow-up (Table 5). Estimates of hypertension incidence, sometimes based on relatively small numbers, varied widely between centres; in Tokyo, rates in Type II diabetic patients were substantially lower than elsewhere.
The BMI was low in the Asian centres and high in both Native American cohorts (Fig. 1). During the follow-up period, body weight decreased by at least $5 \%$ in $29.1 \%$ of the men and $33.5 \%$ of the women. However, $21.9 \%$ of the men and $25.1 \%$ of the women gained $5 \%$ or more in weight over the same period (data not shown). Other changes (not shown but data available on request) include insulin treatment started by $34 \%$ of the people not receiving it at baseline and cigarette smoking newly recorded for $9.2 \%$ of baseline nonsmokers; although in Zagreb, Oklahoma and Arizona, over $50 \%$ reported that they had stopped smoking.

Incidence of vascular complications by centre. The incidence of cardiovascular disease, lower extremity gangrene and/or amputation and retinal and renal microvascular disease are summarised in Figures 2, 3 and 4 respectively.

Angina. The incidence of angina on the basis of a reported 'clinical diagnosis' are shown in Figure 2 (A) and, as in the baseline ascertainment, from the use of the WHO cardiovascular questionnaire (B). The two methods agree fairly closely and show similar incidence patterns among the ten centres, with wide variation (ten to twentyfold) amongst them. Lowest incidences occurred in Tokyo with highest rates reported by women in Warsaw and both sexes in Zagreb. 
men

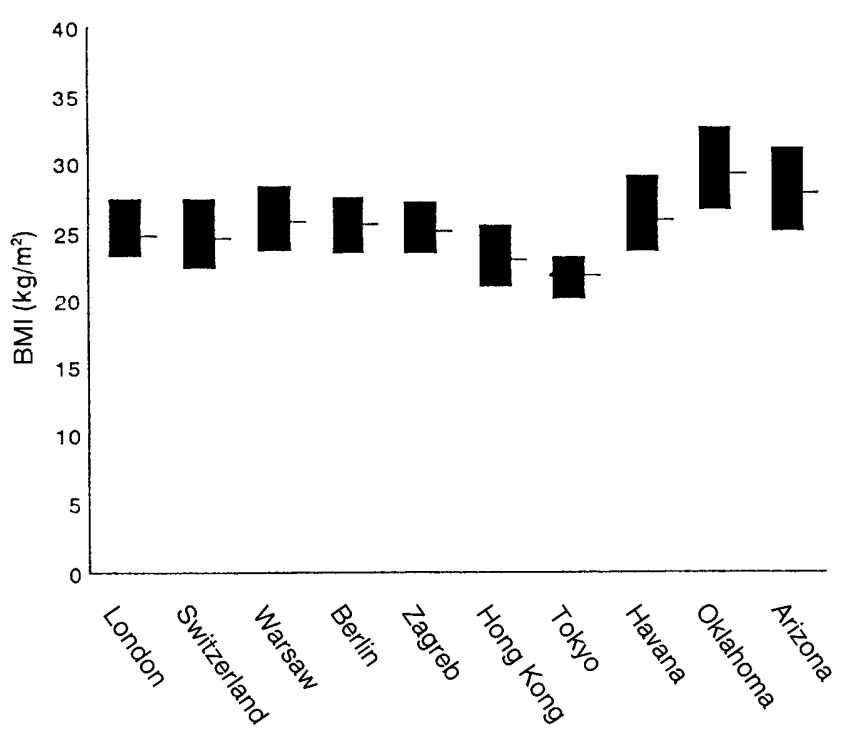

Fig. 1. The distribution of body mass index (BMI) at follow-up by sex and centre. Upper and lower boundaries with $75^{\text {th }}$ and $25^{\text {th }}$ percentiles of the distribution respectively ${ }^{-}$Median, $50 \%$ women

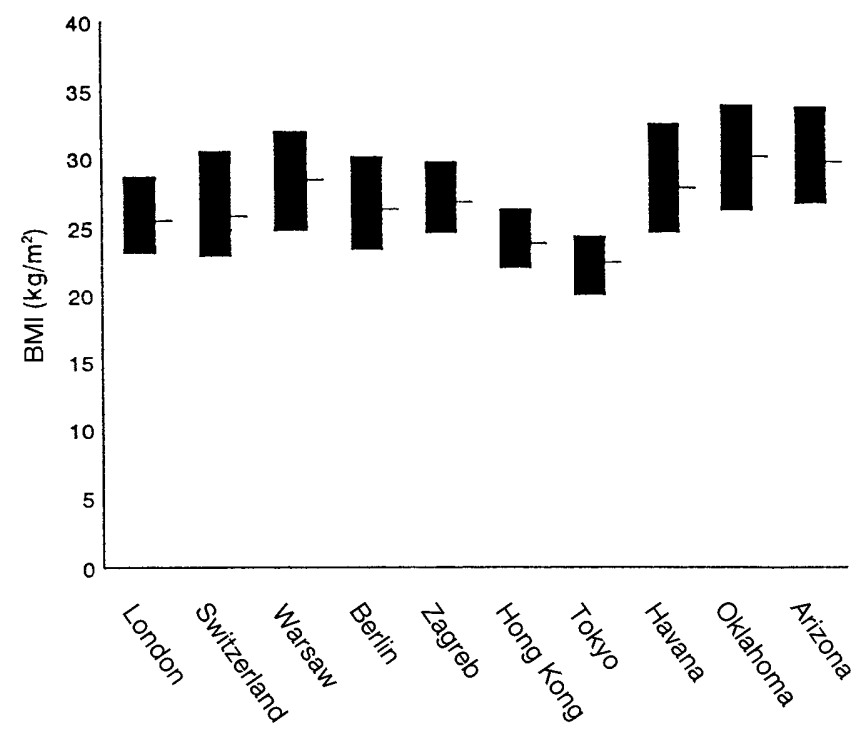

Myocardial Infarction (MI) and ECG ischaemia. The histograms in Figure 2 also show the great variation in reported MI incidence rates between centres and comparable variation in incident ECG abnormalities, especially those indicating probable ischaemia (major $\mathrm{Q} / \mathrm{QS}$ waves). Among the centres, rates of MI incidence broadly parallel the pattern of

Table 4. Characteristics at follow-up by centre

\begin{tabular}{|c|c|c|c|c|c|c|c|c|c|c|c|}
\hline \multirow{2}{*}{$\begin{array}{l}\text { Study } \\
\text { Centre }\end{array}$} & \multirow[b]{2}{*}{ sex } & \multirow{2}{*}{$\begin{array}{l}\text { Age } \\
\text { Mean } \pm \text { SD }\end{array}$} & \multirow{2}{*}{$\begin{array}{l}\text { Duration } \\
\text { of diabetes } \\
\text { Mean } \pm \text { SD }\end{array}$} & \multirow{2}{*}{$\begin{array}{l}\text { Type I } \\
\text { diabetes } \\
n(\%)\end{array}$} & \multirow{2}{*}{$\begin{array}{l}\text { Type II } \\
\text { diabetes } \\
n(\%)\end{array}$} & \multicolumn{2}{|l|}{ Treatment } & \multirow{2}{*}{$\begin{array}{l}\text { SBP } \\
\text { Mean } \pm \text { SD }\end{array}$} & \multirow[t]{2}{*}{ DBP } & \multirow{2}{*}{$\begin{array}{l}\text { Hyper- } \\
\text { tension } \\
n(\%)\end{array}$} & \multirow{2}{*}{$\begin{array}{l}\text { Smoking } \\
n(\%)\end{array}$} \\
\hline & & & & & & $\begin{array}{l}\text { Oral } \\
\text { agents } \\
n(\%)\end{array}$ & $\begin{array}{l}\text { Insulin } \\
n(\%)\end{array}$ & & & & \\
\hline London & $\begin{array}{l}\text { men } \\
\text { women }\end{array}$ & $\begin{array}{l}54.5 \pm 6.1 \\
55.3 \pm 5.7\end{array}$ & $\begin{array}{l}21.3 \pm 10.2 \\
22.6 \pm 10.9\end{array}$ & $\begin{array}{l}118(47.6) \\
127(53.4)\end{array}$ & $\begin{array}{l}130(52.4) \\
111(46.6)\end{array}$ & $\begin{array}{l}44(24.7) \\
39(22.0)\end{array}$ & $\begin{array}{l}123(69.1) \\
135(76.3)\end{array}$ & $\begin{array}{l}137 \pm 20.2 \\
145 \pm 21.8\end{array}$ & $\begin{array}{l}76.3 \pm 10.9 \\
79.6 \pm 12.4\end{array}$ & & \\
\hline Switzerland & $\begin{array}{l}\text { men } \\
\text { women }\end{array}$ & $\begin{array}{l}53.0 \pm 6.3 \\
52.9 \pm 6.3\end{array}$ & & $\begin{array}{r}95(35.2) \\
107(43.5)\end{array}$ & & & & & & & \\
\hline Berlin & $\begin{array}{l}\text { men } \\
\text { women }\end{array}$ & $\begin{array}{l}54.8 \pm 6.3 \\
55.4 \pm 6.2\end{array}$ & & & & & & & & & \\
\hline agreb & $\begin{array}{l}\text { men } \\
\text { women }\end{array}$ & $\begin{array}{l}54.4 \pm 6.3 \\
55.5 \pm 5.5\end{array}$ & & & & & & & $\begin{array}{l}80.5 \pm 11.8 \\
82.0 \pm 12.2\end{array}$ & & \\
\hline Havana & $\begin{array}{l}\text { men } \\
\text { women }\end{array}$ & $\begin{array}{l}52.8 \pm 5.7 \\
52.8 \pm 5.6\end{array}$ & $\begin{array}{l}18.2 \pm 7.4 \\
18.9 \pm 7.8\end{array}$ & & $\begin{array}{l}197(78.5) \\
215(86.4)\end{array}$ & $\begin{array}{l}79(49.1) \\
82(43.2)\end{array}$ & $\begin{array}{l}61(37.9) \\
77(40.5)\end{array}$ & $\begin{array}{l}142 \pm 24.1 \\
147 \pm 27.5\end{array}$ & $\begin{array}{l}80.3 \pm 15.5 \\
82.6 \pm 14.2\end{array}$ & $\begin{array}{r}83(41.3) \\
111(52.1)\end{array}$ & $\begin{array}{l}86(53.7) \\
61(32.3)\end{array}$ \\
\hline Oklahoma & $\begin{array}{l}\text { men } \\
\text { women }\end{array}$ & $\begin{array}{l}58.4 \pm 6.6 \\
58.5 \pm 6.2\end{array}$ & $\begin{array}{l}18.1 \pm 6.2 \\
18.5 \pm 5.8\end{array}$ & $\begin{array}{l}24(9.4) \\
25(6.6)\end{array}$ & $\begin{array}{l}231(90.6) \\
353(93.4)\end{array}$ & $\begin{array}{l}48(35.8) \\
78(33.5)\end{array}$ & $\begin{array}{r}69(51.5) \\
129(55.4)\end{array}$ & $\begin{array}{l}139 \pm 22.1 \\
141 \pm 22.7\end{array}$ & $\begin{array}{l}79.9 \pm 11.3 \\
76.1 \pm 10.8\end{array}$ & $\begin{array}{r}76(45.8) \\
146(52.7)\end{array}$ & $\begin{array}{l}36(28.6) \\
56(24.6)\end{array}$ \\
\hline Arizona & $\begin{array}{l}\text { men } \\
\text { women }\end{array}$ & $\begin{array}{l}54.3 \pm 6.7 \\
55.5 \pm 6.8\end{array}$ & $\begin{array}{l}17.1 \pm 7.0 \\
18.4 \pm 7.2\end{array}$ & $\begin{array}{l}- \\
-\end{array}$ & $\begin{array}{c}83(100) \\
144(100)\end{array}$ & $\begin{array}{l}21(35.6) \\
37(30.6)\end{array}$ & $\begin{array}{l}20(33.9) \\
55(45.5)\end{array}$ & $\begin{array}{l}126 \pm 22.1 \\
127 \pm 21.8\end{array}$ & $\begin{array}{l}78.7 \pm 10.1 \\
72.9 \pm 12.1\end{array}$ & $\begin{array}{l}24(34.8) \\
47(36.7)\end{array}$ & $\begin{array}{l}18(31.0) \\
17(14.0)\end{array}$ \\
\hline All & $\begin{array}{l}\text { men } \\
\text { women }\end{array}$ & $\begin{array}{l}54.9 \pm 6.3 \\
55.4 \pm 6.3\end{array}$ & $\begin{array}{l}18.6 \pm 7.6 \\
18.9 \pm 7.7\end{array}$ & $\begin{array}{l}611(28.6) \\
577(25.3)\end{array}$ & $\begin{array}{l}1528(71.4) \\
1706(74.7)\end{array}$ & $\begin{array}{l}467(31.8) \\
487(28.7)\end{array}$ & $\begin{array}{r}835(56.9) \\
1021(60.1)\end{array}$ & $\begin{array}{l}140 \pm 21.1 \\
144 \pm 24.1\end{array}$ & $\begin{array}{l}80.2 \pm 11.9 \\
79.2 \pm 12.1\end{array}$ & $\begin{array}{l}611(34.2) \\
903(47.4)\end{array}$ & $\begin{array}{l}540(37.1) \\
346(20.5)\end{array}$ \\
\hline
\end{tabular}

SBP, systolic blood pressure; DBP, diastolic blood pressure.

SBP, DBP, hypertension, treatment and smoking status were based on follow-up interview and examination information 
Table 5. Incidence of hypertension at follow-up by type of diabetes, sex and centre

\begin{tabular}{|c|c|c|c|c|c|c|c|c|c|c|c|c|}
\hline \multirow[t]{3}{*}{ Centre } & \multicolumn{6}{|c|}{ Type I (insulin-dependent) diabetes mellitus } & \multicolumn{6}{|c|}{ Type II (non-insulin-dependent) diabetes mellitus } \\
\hline & \multicolumn{3}{|l|}{ Men } & \multicolumn{3}{|l|}{ Women } & \multicolumn{3}{|l|}{ Men } & \multicolumn{3}{|l|}{ Women } \\
\hline & $\begin{array}{l}\text { No. } \\
\text { Subjects }\end{array}$ & \multicolumn{2}{|c|}{ Incidence } & $\begin{array}{l}\text { No. } \\
\text { Subjects }\end{array}$ & \multicolumn{2}{|c|}{ Incidence } & $\begin{array}{l}\text { No. } \\
\text { Subjects }\end{array}$ & \multicolumn{2}{|c|}{ Incidence } & $\begin{array}{l}\text { No. } \\
\text { Subjects }\end{array}$ & \multicolumn{2}{|c|}{ Incidence } \\
\hline London & 78 & 9 & 11.5 & 79 & 15 & 19.0 & 68 & 18 & 26.5 & 44 & 14 & 31.8 \\
\hline Switzerland & 51 & 12 & 23.5 & 59 & 22 & 37.3 & 80 & 21 & 26.3 & 46 & 18 & 39.1 \\
\hline Warsaw & 67 & 17 & 25.4 & 59 & 25 & 42.4 & 59 & 15 & 25.4 & 74 & 31 & 41.9 \\
\hline Hong Kong & 34 & 0 & 0.0 & 25 & 7 & 28.0 & 59 & 13 & 22.0 & 88 & 27 & 30.7 \\
\hline Tokyo & 16 & 5 & 31.3 & 18 & 5 & 27.8 & 102 & 10 & 9.8 & 89 & 18 & 20.2 \\
\hline Havana & 23 & 8 & 34.8 & 19 & 10 & 52.6 & 90 & 35 & 38.9 & 93 & 38 & 40.9 \\
\hline Oklahoma & 5 & 2 & 40.0 & 7 & 6 & 85.7 & 80 & 41 & 51.3 & 130 & 60 & 46.2 \\
\hline Arizona & - & - & - & - & - & - & 39 & 11 & 28.2 & 80 & 19 & 23.8 \\
\hline Total & 332 & 73 & 22.0 & 329 & 119 & 36.1 & 712 & 202 & 28.4 & 756 & 280 & 37.0 \\
\hline
\end{tabular}

incident angina with the exception of the high MI incidence in London and in Swiss men, findings supported by the higher rates of 'probable ischaemia' on ECG. The Tokyo cohort shows notably low incidence of both clinical and ECG ischaemia whereas the Oklahoma American Indian sample shows strikingly high rates of both.

Stroke. The geographical distribution profile of stroke incidence differs distinctly from that of myocardial ischaemia (Fig.2). In men and women, rates in Hong Kong and Arizona are equal to or exceed the high Oklahoma incidence.

Lower extremity gangrene and/or amputation. The two Native American centres stand out with their high incidence of first events of lower extremity gangrene/amputation (Fig. 3). Their rates in men exceed those in women twofold and those in other centres 10 times or more. London, Hong Kong, Tokyo, and Zagreb had generally low amputation rates.

Retinopathy and severe visual impairment. The variation in manifestations of diabetic eye disease incidence (Fig. 4) is substantially less than that of macrovascular disease incidence (Fig.2). Oklahoma has high rates of any retinopathy and its severe proliferative component but relatively low rates of reported severe visual impairment. Zagreb and Hong Kong report high incidence of any retinopathy and the high proliferative component in the former is accompanied by relatively high rates of severe visual impairment. In Berlin, no new severe visual impairment was reported for men and little for women.

Proteinuria and renal failure. Follow-up urine tests (Fig. 4) with albustix in those negative for protein at baseline showed the highest positives rates in the Oklahoma and Arizona American Indians, followed by Hong Kong, Zagreb and Switzerland. Quantitative assays of urinary albumin-to-creatine ratios confirm these findings. Incidence of renal failure was also highest in the two American Indian centres who thus lead distinctively in all the indices of renal disease

\section{Discussion}

The re-ascertainment of the original recruits to the WHO multinational study in the 10 centres reported here was reasonably successful. Rates of complete loss to follow-up were below $7 \%$ in all except Zagreb and Hong Kong. In Hong Kong, non-participants differed little from respondents at baseline, but in Zagreb their baseline characteristics suggest underestimation of vascular outcomes in the participating group. In the 10 centres, $540(11.4 \%)$ had died during follow-up with all-cause death rates substantially higher in men than women and ranging from $3.0 \%$ in Tokyo women to $21.7 \%$ in Warsaw men (Table 1). In high mortality centres (e.g. Warsaw, Berlin, Oklahoma) study outcomes, such as angina and myocardial infarction, gangrene and/or amputation and severe eye and kidney disease, might have preceded death. The longer observation time for the Oklahoma cohort would increase the number of events. It might even have influenced calculated incidence rates; although such rates take years of observation time into account, the growth of risk for many events is likely to accelerate.

Risk factors. During the follow-up period the relative frequency of some of the baseline characteristics changed, for example adiposity, insulin use, smoking habit and hypertension. Nearly one in three subjects lost weight but one in four gained; one third started insulin treatment and $32 \%$ of those at risk were documented as becoming hypertensive, though in some only on the basis of a single high pressure measured at follow-up. It is difficult to interpret such risk factor 

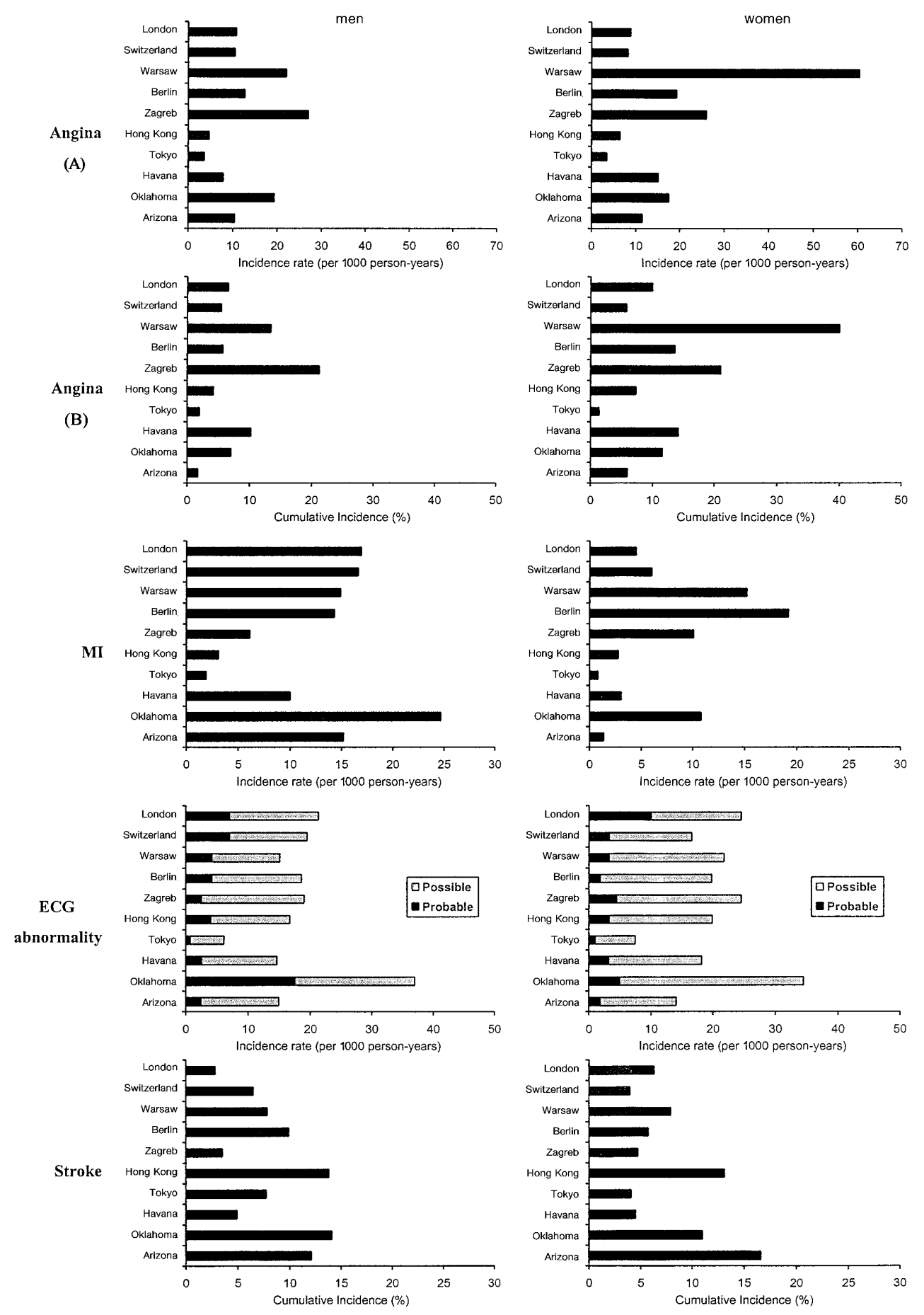

Fig. 2. Incidence of indices of cardiovascular disease by sex and centre Angina (A) from clinical diagnosis reported on direct questioning; Angina (B) by the WHO questionnaire. MI, Myocardial infarction. ECG abnormality by Minnesota Code (see Appendix 1)

changes in relation to incident events; they could be causal or consequential, or both could be driven by some independent factor(s).

The follow-up period was sufficient to provide a large number of vascular disease events for analysis.
Their incidence varied widely among the different geographical and ethnic groups but broadly reflected the prevalence study findings $[2,12,13]$. Individual outcome items of vascular disease, summarised here, are dealt with in greater detail in accompanying papers.

Macrovascular outcomes. In macrovascular (atherosclerotic) disease outcomes, a striking feature is the contrast between the low incidence of the manifestations of ischaemic heart disease in the Hong Kong and Tokyo centres, confirming earlier reports 

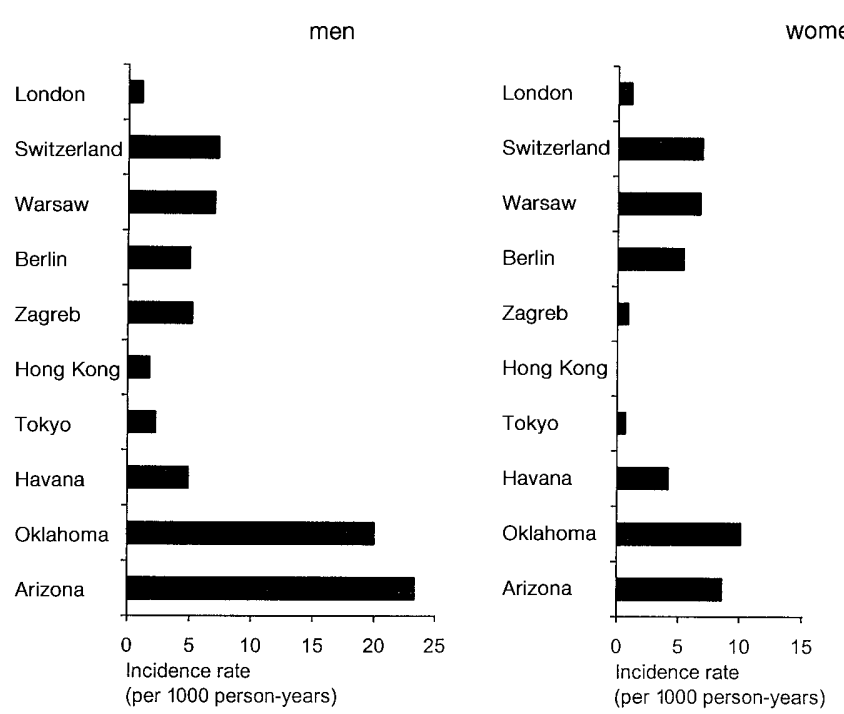

Fig.3. Incidence of first lower-extremity gangrene/amputation by sex and centre

$[14,15]$, and the high rates in Oklahoma (but not Arizona) American Indians. The high reported incidence of angina in women from Warsaw is unaccompanied by correspondingly high rates of ECG abnormality, though they do have the second highest rate of all-cause mortality. Transcultural comparisons of subjective symptom data such as chest discomfort must be treated with caution. Despite their low rates of ischaemic heart disease, stroke rates in Hong Kong were at least as high as in Oklahoma, with comparably high rates in Arizona American Indians.

Lower-extremity gangrene and/or amputation. Despite their different incidences of ischaemic heart disease, both American Indian groups reported comparably high rates of lower extremity gangrene and/or amputation with rates in men exceeding those in women more than in the other centres, supporting the findings of other studies of diabetes in Pima and Oklahoma Indian people $[16,17]$. The common protocol firmly directed examination towards ischaemic disease as the cause of gangrene and amputation but it is likely that coexistent diabetic neuropathy and general disease management were also important contributory determinants.

Microvascular outcomes. Both American Indian cohorts showed great vulnerability to the diabetes specific microvascular disease outcomes concurring with previous reports in their high incidence of retinopathy $[18,19]$, proteinuria $[20,21]$ and renal failure [22]. The relatively low rates of severe visual impairment in the Oklahoma cohort could in part be explained by their greatly increased mortality risk selec- tively removing those with the worst retinopathy. Proteinuria rates are also notably higher in the Hong Kong than in the Tokyo centre, a difference supported by the quantitative estimates of urinary albumin concentration. Numbers of people progressing to renal failure might be underestimated when associated with high risk for cardiac death as in many western countries, or relatively overestimated when coronary heart disease risk is low, as in Japan. The highest rates of renal disease in the Arizona Indians could thus in part be attributable to their anomalously low cardiovascular risk status.

Conclusion. This descriptive account demonstrates the existence of large variations in estimates of the rates of emergence and evolution of the vascular complications of diabetes among the 10 centres contributing to the follow-up of the WHO Multinational Study of vascular disease in diabetes. As with the prevalence study, variation among centres was substantially greater for incidence of macrovascular disease than for microvascular disease. The Oklahoma centre-based native American cohort appeared particularly susceptible to both microvascular and macrovascular complications and the Tokyo Japanese cohort relatively spared. Observer variation, selection biases and ascertainment problems inevitably made some contribution to these reported differences but the study has the advantage that the groups worked to agreed definitions and a standard protocol, using simple methodologies. Whenever possible, analyses were done centrally. Some of the differences described are likely to be real.

\section{Appendix 1}

\section{Definitions of Vascular Disease Outcomes [2]}

1. Angina pectoris

Form IIA." Yes to question "Have you ever had angina pectoris?" or WHO angina questionnaire positive or

Form IIB.* Confirmed record of angina pectoris

2. Myocardial Infarction (MI)

Form IIA. Yes to question "Have you ever had a heart attack?"

or

Form IIB. Confirmed record of heart attack. or

Death Certificate: ICD-9 codes 410-414

3. ECG Abnormalities

Centrally Minnesota-coded 12-lead electrocardiogram (ECG) by two independent observers with codes grouped as follows:

a. CHD Probable: Codes 1.1 and 1.2 (large Q and QS waves) and Code 7.1 (complete left bundle branch block).

b. CHD Possible: Code 1.3 (small Q waves), Codes 4.1, 4.2 and 4.3 (S-T segment abnormalities) and Codes 5.1, 5.2 and 5.3 (T wave abnormalities) 

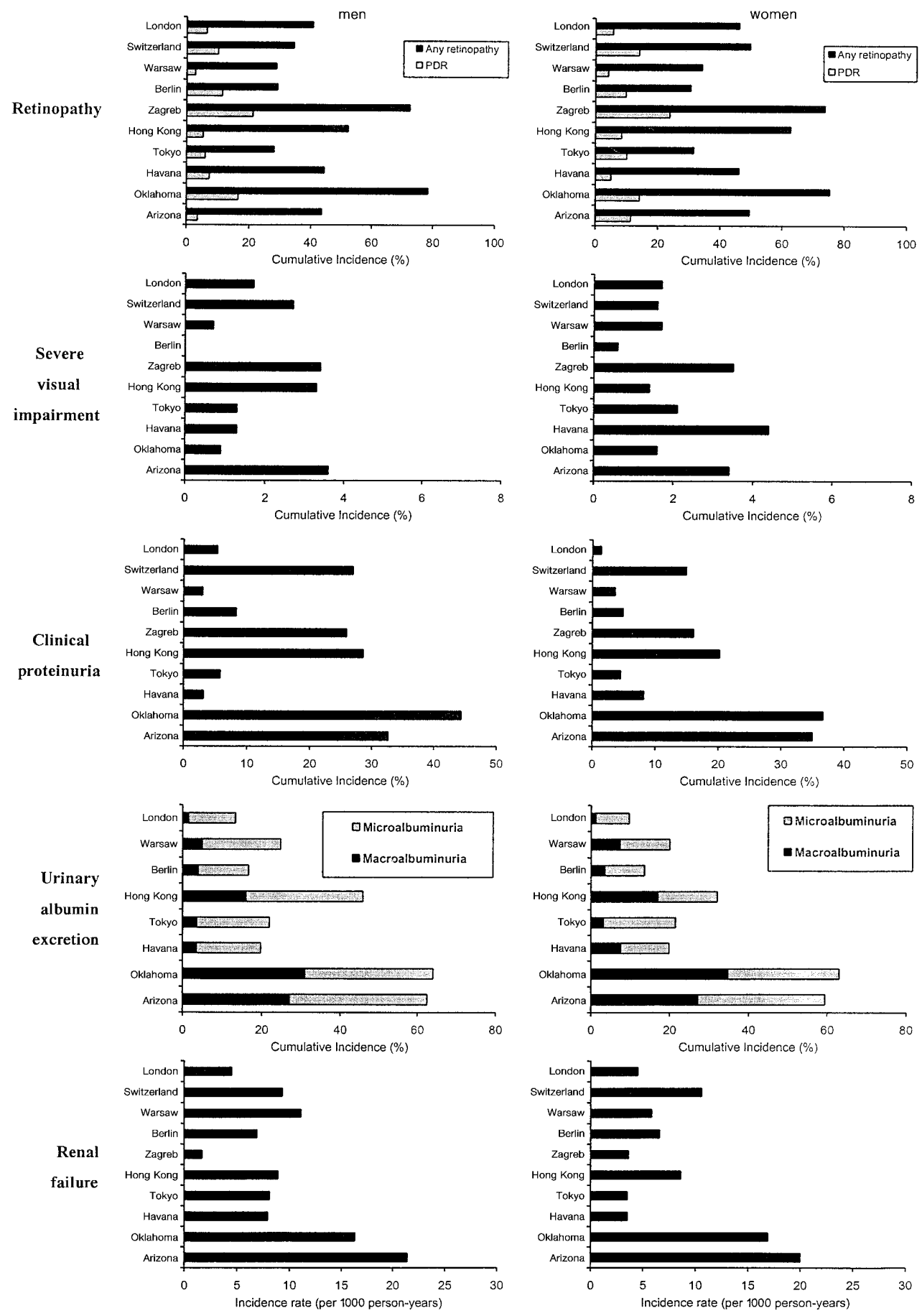

Fig. 4. Incidence of indices of retinal and renal disease by sex and centre (see Appendix 1)

\section{Stroke}

Form IIA. Yes to question "Have you ever had cerebrovascular disease (stroke)?" or

Form IIB. Confirmed record of stroke. or

Death certificate: ICD-9 codes 430-438 (cerebrovascular disease).
5. Lower-extremity gangrene or amputation

Form IIA. Yes to question "Have you ever had ischaemic gangrene or had an amputation for arterial obstruction?" or

Form IIB. Confirmed record of gangrene or amputation. or

Death certificate: ICD-9 codes 785.4 (gangrene) and 997.6 (stump complications).

6. Retinopathy

Direct ophthalmoscopic fundus examination through dilated pupils using standardised baseline protocol. Non-proliferative diabetic retinopathy (NPDR): one or more microaneurysms or haemorrhages \pm soft or hard exudates. Prolifera- 
tive diabetes retinopathy (PDR): definite retinal neovascularisation, vitreous hemorrhages or history of photocoagulation treatment. Any retinopathy: either NPDR or PDR.

7. Severe Visual Impairment

Form IIA. Yes to question "Does the patient have significant visual disability not corrected by spectacles?" and patient reported as being totally blind, having only light perception or being able only to count fingers. or

Form IIB. Confirmed record of serious visual defect.

8. Clinical proteinuria

Clinical proteinuria was defined as a level of + or more using the Albustix method carried out in the central laboratory in Phoenix, Arizona, USA.

9. Urinary albumin excretion

The urinary albumin to urinary creatinine ratio (UAC) was used as an estimate of albumin excretion rate. Increased urinary albumin excretion was defined as a UAC ratio of $\geq 30 \mathrm{mg} / \mathrm{g}$ and was subdivided into two categories: microalbuminuria with a UAC ratio of 30-299 mg/g and macroalbuminuria with a UAC ratio of $\geq 300 \mathrm{mg} / \mathrm{g}$.

10. Renal failure

Form IIA. Yes to question "Are you currently receiving renal dialysis or have you had a renal transplant?" or

Form IIB. Confirmed record of renal failure. or

Death certificate: ICD-9 codes 585-589 (chronic renal failure, unspecified renal failure) and 250.3 (diabetes with renal manifestation).

\footnotetext{
* Copies of forms IIA and IIB are available on the Internet www:http://www.ucl.ac.uk/epidemiology/eurodiab/eurodiab. htm) or on request to: Elisa T Lee, Ph.D, College of Public Health, University of Oklahoma Health Sciences Centre, PO Box 26901, Oklahoma City, OK 73190, Tel.: (405)2713090, Fax: (405) 271-4390
}

\section{Appendix 2}

\section{List of Investigators}

London, UK: J Fuller, RJ Jarrett, H Keen, NJ Morrish, and PJ Watkins. Bern Switzerland: A Teuscher, T Teuscher, PP Studer, P Diem and JB Herman. Warsaw, Poland: A Czyzyk, D Janeczko, and J Kopczynski. Berlin, Germany (former GDR): M Raskovic, V Schliack, M Ratzmann. Zagreb, Croatia: Z Skrabolo, I Aganovic, A Stavljenic and G Roglic. Hong Kong: RTT Young, K Lam, and J Ma. Tokyo, Japan: K Kosaka and E Miki. Havana, Cuba: O Mateo de Acosta, O Diaz, X Quesada and A Hernandez Yero. Oklahoma, US: E Lee. Arizona, US: PH Bennett, DJ Pettitt, and RG Nelson.

Mortality committee. K. Ball, E. Jepson, R. J. Jarrett (Chairman), N. Morrish, J. Fuller (London).

Acknowledgements. Data management and statistical analyses were carried out at the Data Coordinating Centre in Oklahoma and supported by a contract (N01-DK-8-2232) from the National Institute of Diabetes and Digestive and Kidney Diseases (Program Director, M Harris). We thank Dr R.F. Hamman (Denver, USA) for helpful advice and discussion. We also thank Prof. R. J. Jarrett, Dr K. Ball and Dr E. Jepson for their services to the Mortality Committee and Ms T. West for preparing the papers in this supplement.

\section{References}

1. Jarrett RJ, Keen H, Grabauskas V (1979) The WHO multinational study of vascular disease in diabetes: 1 . General description. Diabetes Care 2: 175-186

2. Diabetes Drafting Group (1985) Prevalence of small vessel and large vessel disease in diabetic patients from 14 centres: The World Health Organization Multinational Study of Vascular Disease in Diabetes. Diabetologia 28: 615-640

3. Fuller J., Head J, and the WHO Multinational Study Group (1989) Blood pressure, proteinuria and their relationship with circulatory mortality: WHO Multinational Study of Vascular Disease in Diabetes. Diabetes Metabol 15: $273-277$

4. Head J, Fuller H (1990) International variations in mortality among diabetic patients: the WHO Multinational Study of Vascular Disease in Diabetes. Diabetologia 33: 477-481

5. Rose G, Blackburn H (1968) Cardiovascular Survey Methods. WHO Monograph Series No. 56, WHO, Geneva

6. Vasquez B, Flock EV, Savage PJ et al. (1984) Sustained reduction of proteinuria in Type II (non-insulin-dependent) diabetes following diet-induced reduction of hyperglycaemia. Diabetologia 26: 127-133

7. Fuller J, Lee ET, Lu M, WHO MSVDD Investigators (2001) Hypertension and the development of vascular complications: The WHO multinational study of vascular disease in diabetes (MSVDD). Diabetologia 44 [Supp 2]: S54-S 64

8. Miki E, Lee ET, Lu M, WHO MSVDD Investigators (2001) Incidence of and risk factors for renal failure: The WHO Multinational Study of Vascular Disease in Diabetes (MSVDD). Diabetologia 44 [Supp 2]: S31-S36

9. Lee ET (1992) Statistical Methods for Survival Data Analysis, $2^{\text {nd }}$ edn, Wiley, New York

10. SAS institute (1985) SAS User's Guide: Statistics. Version Edition, Cary, NC, SAS Inst

11. West KM, Ahuja MMS, Bennett PH et al. (1983) The role of circulating glucose and triglyceride concentrations and their interactions with other "risk factors" as determinants of arterial disease in nine diabetic population samples from the WHO Multinational Study. Diabetes Care 6: 361-369

12. Keen H, Jarrett RJ (1979) The WHO multinational study of vascular disease in diabetes: 2. Macrovascular disease prevalence. Diabetes Care 2: 187-195

13. Jarrett RJ, Keen H (1979) The WHO multinational study of vascular disease in diabetes: 3. Microvascular disease. Diabetes Care 2: 196-201

14. Jarrett R, Keen H, Chakrabarti R (1982) Diabetes, hyperglycaemia and arterial disease. In: Keen H, Jarrett J (eds) Complications of diabetes 2nd edn. Edward Arnold, London, pp 179-203

15. Goto Y, Toyoto T, Masuda M, Utumi N, Katsuse T (1976) Vascular complications of diabetic patients in Japan. In: Baba S, Goto Y, Fukui I (eds) Diabetes in Asia Excerpta Medica, Amsterdam-Oxford, pp. 177-182

16. Nelson RG, Gohdes DM, Everhart JE et al. (1988) Lowerextremity amputations in NIDDM: 12-yr follow-up study in Pima Indians. Diabetes Care 11: 8-16

17. Lee JS, Lu M, Lee VS, Russell D, Bahr C, Lee ET (1993) Lower-extremity amputation: incidence, risk factors and mortality in Oklahoma Indian Diabetes Study. Diabetes 42: 876-882

18. Lee ET, Lee VS, Kingsley RM et al. (1992) Diabetic retinopathy in Oklahoma Indians with NIDDM: incidence and risk factors. Diabetes Care 15: 1620-1627 
19. Lee ET, Lee VS, Lu M, Russell D (1992) Development of proliferative retinopathy in NIDDM, A follow-up study of American Indians in Oklahoma. Diabetes 41: 359-367

20. Nelson RG, Newman JM, Knowler WC et al. (1988) Incidence of end-stage renal disease in Type II (non-insulin-dependent) diabetes mellitus in Pima Indians. Diabetologia 31: 730-736
21. Nelson RG, Knowler WC, Pettitt DJ, Saad MF, Bennett PH (1993) Diabetic kidney disease in Pima Indians. Diabetes Care 16: 335-341

22. Lee ET, Lee VS, Lu M, Lee JS, Russell D, Yeh JL (1994) Incidence of renal failure in NIDDM: The Oklahoma Indian Diabetes Study. Diabetes 43: 572-579 